\title{
A cytogenetic photomap from ovarian nurse cell polytene chromosome of Anopheles stephensi (Diptera: Culicidae): a comparative study
}

\author{
Deepak Sanil $^{1,2,3} \cdot$ Vinaya Shetty $^{1,2} \cdot$ D. V. Purushothama ${ }^{4} \cdot$ N. J. Shetty ${ }^{1}$ (I)
}

Received: 8 May 2017 / Accepted: 5 July 2018 / Published online: 18 July 2018

(c) Archana Sharma Foundation of Calcutta 2018

\begin{abstract}
Polytene chromosome banding patterns have long been used to infer the degree of relatedness among taxa and as a standard reference for locating genes, puffs, and inversion breakpoints of unique gene arrangements. Chromosome comparisons between the species over the time have shown organizational changes in patterns which have resulted in adaptive advantages. An attempt has been made to prepare chromosome map from the ovarian nurse cell of Anopheles (Cellia) stephensi Liston, and to re-evaluate the physical map of this species. The photomaps prepared, were compared with other available maps of the past for the same species. The images of the polytene chromosomes have been straightened and divided by numbered divisions and lettered subdivisions. Tentative inversion breakpoints occurring naturally and that recorded from different insecticide resistant strains of An. stephensi is described in the present map. Some of the re-arrangements acquired have been highlighted in the paper in view to provide an overview of the importance of cytogenetic maps to Anopheles biology and the concept of chromosome evolution.
\end{abstract}

Keywords Anopheles stephensi $\cdot$ Polytene chromosome $\cdot$ Cytogenetic photomap $\cdot$ Puffs $\cdot$ Interbands

\section{Introduction}

Anopheles stephensi Liston (Diptera: Culicidae) is an important malaria vector in the Indian subcontinent and the Middle East. Among anophelines, An. stephensi is the most ideal species for experimental genetic and cytogenetic studies because of its amenability to laboratory colonization and maintenance [71]. Use of An. stephensi as a model system has allowed significant progress in studying

N. J. Shetty

shetty_nj@yahoo.co.in

Deepak Sanil

sanildeepak@gmail.com

1 Centre for Applied Genetics, Bangalore University, Bengaluru 560 056, India

2 Department of Biological Sciences, Poornaprajna Institute of Scientific Research, Bengaluru, India

3 Bhuvaneshwari Education Society's, PJ Pancholia School, Kandivali, Mumbai 400 067, India

4 Department of Zoology, Bangalore University, Bengaluru 560 056, India mosquito-parasite interactions $[1,32,40]$. Polytene chromosomes are the consequences of multiple DNA replications without division and are characterized by their great size and distinguished banding patterns. The construction and depiction of the polytene chromosomes (salivary or ovarian) into standard chromosome maps are a key objective of cytogenetic analysis aimed at inferring the adapative advantages of anopheline species [15, 36]. Chromosome studies have led to an understanding and identification of sibling species within the family Culicidae [17, 37, 56, 74, 75, 77]. Variations in the anopheline polytene chromosomes, as evidenced by a comparative study among close-linked species, involve changes in banding series resulting from the fixed paracentric inversions and differences in chromosomal polymorphism, have led to findings of sibling species of malaria vectors, e.g., An. gambiae complex [21, 30], An. culicifacies complex [31, 76], An. subpictus complex [78] and An. dirus complex [2]. Investigating chromosome banding pattern takes on a pivotal role in evolutionary studies, first as genetic markers, in which, the chromosomal inversions are considered alleles and are used to examine adaptive polymorphism for ecological requirements, increasing fitness and secondly, as tracers of organic adapation $[39,52,73]$. 
The comparative chromosome study is an indispensable tool in the classification of mosquitoes based on its epidemiological significance $[46,48,58]$. Physical mapping has facilitated the whole genome sequence assembly as in the case of the major African malaria vector An. gambiae [63]. Chromosome mapping is also used in identifying quantitative trait loci conferring insecticide resistance, vector competence and in molecular taxonomy using different DNA probes for locating specific genes using polytene chromosome maps as reference standards [16, 23, 24, 26, 34, 81].

In this paper, we tried to compare our cytogenetic photomap with the work of some of the pioneer workers who have earlier described and presented the ovarian nurse cell chromosome photomap of An. stephensi. Additionally, we have presented the tentative breakpoint region for natural inversions as well as inversions associated with insecticide resistance studied in our laboratory. Our photomap can easily be homologized with the chromosome map already available for An. stephensi. This photomap may be useful in providing a suitable basis for further comparative genomics, which can be used for defining the extent of chromosome conservation and rearrangement within the species across the time.

\section{Materials and methods}

\section{Mosquito collection and rearing}

Freshly collected larvae of An. stephensi from Jayanagar, Bangalore were used for the study. These field-collected larvae were reared on a protein-rich diet consisting of a finely powdered mixture of dog biscuit and fish feed. They were maintained in laboratory at $25 \pm 1{ }^{\circ} \mathrm{C}$ and $75 \pm 5 \%$ of relative humidity with $14-\mathrm{h}$ photoperiods, following the procedure of Shetty [70]. Pupae formed were transferred into widemouthed bottles and placed into their respective cages for emergence. The adults were fed on $10 \%$ sucrose, in 8 in. $\times 8$ in. $\times 8$ in. iron cages, covered with cotton net cloth. Females were provided with restrained mice or pigeon as a source of blood meal. Some of these female mosquitoes were used for chromosome preparation and rest was used for stock maintenance for future studies.

\section{Chromosome preparation}

Polytene chromosomes of ovarian nurse cells of semigravid females of An. stephensi were prepared following the procedures of French et al. [25] and Gayathri and Shetty [28]. Five- to seven-day-old females of An. stephensi were blood-fed on restrained mice. After 28-30 h, these semigravid females were individually separated into a test tube and immobilized by striking the lower end of the test tube gently against the palm. The mosquito was then placed on a slide and a drop of dilute Carnoy's fixative (Carnoy's fixative/distilled water, 1:19) was added. A quick and successful method to remove the ovaries was to hold the anterior of the abdomen with one needle (left hand) and the penultimate segment of the abdomen with the other and then to give a sharp pull posteriorly to cut the last two segments. The abdomen was then gently pressed, spilling the ovaries. The ovaries were separated from the debris and then fixed in Carnoy's fixative (methanol/acetic acid, 3:1) for 2-4 min.

For routine staining of polytene chromosomes, synthetic orcein was used for lacto-aceto-orcein (LAO). Orcein was mixed with glacial acetic acid, in the following proportion: $2 \mathrm{~g}$ of orcein in $50 \mathrm{ml}$ of $85 \%$ lactic acid and $50 \mathrm{ml}$ of $100 \%$ glacial acetic acid. The stock solution of LAO was stored in a cool and dry place. It was further diluted in lactic acid and acetic acid (1:1) prior to use to avoid overstaining. After fixation, the material was stained with a drop of LAO for 15-20 min. After staining, 60\% acetic acid was added and a clean coverslip was placed on the top of the material. Gentle pressure was applied to obtain an even spread. The coverslip was sealed with nail polish and the slide was examined under the microscope.

The nomenclature of banding pattern was followed, according to the method of Coluzzi et al. [19]. The zones and sub-zones, carrying various aberrations, were identified and assigned their exact location on the chromosome. The chromosome banding pattern were carefully studies and compared with existing standard polytene chromosome map of Coluzzi et al. [19], Sahabi et al. [59], Redfern [57], Gayathri and Shetty [27] and Sharakhova et al. [65] for An. stephensi.

These temporary preparations were examined and photographed at $40 \times$ magnification using a Lieca microscope. The identification of each chromosome and its right and left arms was deduced from the size, characteristic shape, and banding pattern of the free and centromeric ends along with several prominent puffs and sets of dark bands in other regions. The ovarian nurse cell polytene chromosome photomap (Fig. 1) was developed after studying the photographs and slides under the microscope. For the preparation of the photomap, scanned polytene chromosome photo were used to develop a merged image with retaining the finest details of banding pattern using Adobe Photoshop CS4 version 11.0 software. The digital images of chromosomes were straightened using the "straighten-curved-objects" plugin in the Image J software [38].

\section{Results and discussion}

Malaria is an important disease that has a global distribution and significant health burden, particularly in parts of sub-saharan Africa and Indian sub-continent [50]. It is 
$\mathbf{X}$

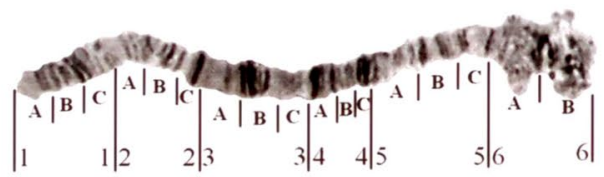

$2 \mathbf{R}$

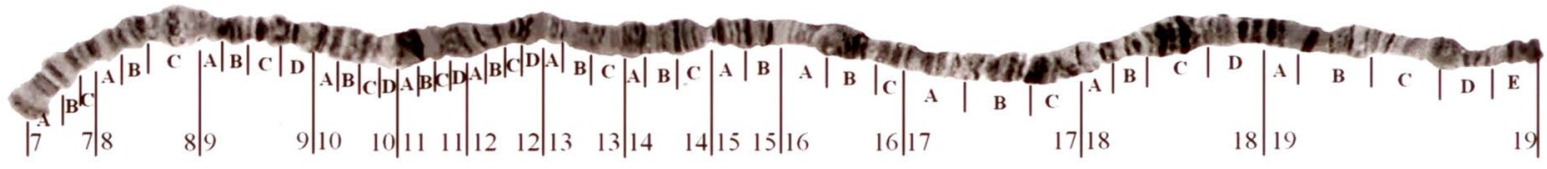

$2 \mathbf{L}$

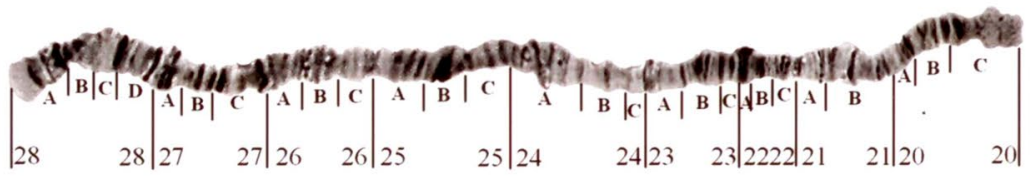

3R

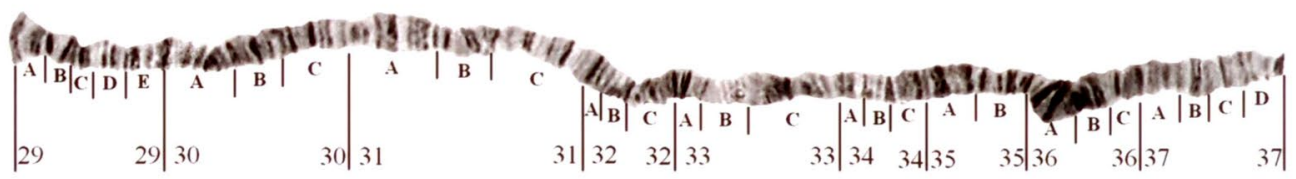

$3 \mathbf{L}$

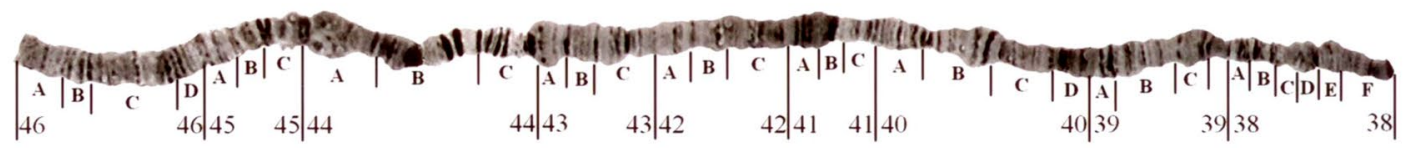

Fig. 1 Standard photomap of the polytene chromosomes from the Anopheles stephensi ovarian nurse cells

responsible for over one million deaths per year and infecting more than 250 million people [47]. An obligatory vector for human malaria, anopheline mosquito species affects millions of people residing in malaria endemic countries [9]. An important approach for reducing or eliminating malaria is by vector control, which is largely exercised through the usage of insecticides. However, mosquitoes have developed resistance to all the major groups of insecticides [6]. Insecticide resistance is one of the finest cases of rapid adaptation to selection pressure, such an incredible ability highly depends on its genetic variability [52]. Data on genetic variability within and among mosquito populations are vital for understanding the disease epidemiology [79]. Emergence of populations of Anopheles capable of withstanding lethal doses of insecticides, the effectiveness of insecticide-based vector control is severely affected [33].

A photomap of the An. stephensi polytene chromosomes were prepared from ovarian nurse cells with numbered divisions and lettered subdivisions (Fig. 1). The borders and nomenclature for divisions and subdivisions have been adopted from a cytogenetic map for An. stephensi by Coluzzi et al. [18], Gayathri and Shetty [28] and Sharakhova et al. $[65,67]$. The depiction of the polytene chromosome banding pattern of the present study and its comparison with polytene chromosome map produced in the initial stages of cytogenetic investigation on An. stephensi are presented in the paper. Tentative breakpoint region for natural inversions from wild type strains of An. stephensi from Bangalore [28] and laboratory induced insecticide resistant associated inversions [72] are also highlighted in the report.

\section{Description of the landmarks useful for arm identification}

The diploid karyotype of 6 chromosomes in the metaphase cells of An. stephensi consists of a pair of sex chromosomes (XX, female; XY, male) which are acrocentic in nature and larger autosomal pairs 2 and 3. Pair 2 is larger 
submetacentric homologues whereas, pair 3 is somewhat smaller metacentric homologues. This is the standard chromosome pattern that is pragmatic in the majority of species of subgenus Cellia. The ovarian nurse cell chromosome complement consists of five elements of synapsed polytene chromosomes appearing as five arms weakly attached in the region of the centromere, with a short telomeric X chromosome and two pairs of longer metacentric autosomes with arms of distinguishable length.

\section{X chromosome}

The $\mathrm{X}$ chromosome is the shortest in the complement. It is generally appeared isolated in squash preparation and could be readily recognized by its length and characteristic banding pattern of lightly stained telomeric end (region 1A) and two wide heterochromatic areas on the centromeric end (regions 6A and 6B). The most characteristic feature of the center section of this chromosome is the presence of 4-5 sharply stained bands, which occupy subzones $3 \mathrm{~B}$. The centromeric zone 6 commences with a dumbbell shaped band in subzone $6 \mathrm{~A}$ and $6 \mathrm{~B}$.

\section{Chromosome 2R (2)}

The right arm of chromosome 2 is the longest element among the 4 autosomal arms. The telomeric region 7A has three distinct, narrow bands at the end followed by the puff in subzone 7B which is the recognized feature of arm $2 \mathrm{R}$. In zone 9, a set of 3 heavy bands each in zone $9 \mathrm{~B}$ and $9 \mathrm{C}$ are more prominent than the rest, whereas zones 10 have several intensely stained bands. Zone 12 carries as many as 6 highly stained bands in subzone $12 \mathrm{~A}, 12 \mathrm{~B}, 12 \mathrm{C}$ and $12 \mathrm{D}$. There is distinct puff seen in zones 14 of the chromosome arm $2 \mathrm{R}$. The peri-centromeric area can be acknowledged by a diffuse regional 19B and 19C. Region 19D consists of small puff followed by three thin deeply stained bands.

\section{Chromosome 2L (3)}

Chromosome $2 \mathrm{~L}$ is significantly smaller than chromosome $2 \mathrm{R}$, due to its submetacentric nature. The concluding part of telomeric region is squarish and consists of two dark, narrow bands in the proximal portion of region 28A. There is prominently large diffused area visible in region $20 \mathrm{~B}$. In zone 27 , as many as 4 evenly spaced dark bands in both $27 \mathrm{~B}$ and $27 \mathrm{C}$ are present. Subzones 26 consists of broken bands located at 26B. A series of 8 heavy bands in zone 25 and are well marked in $2 \mathrm{~L}$. The centromeric end of $2 \mathrm{~L}$ is light, and granulated. The area between subzones $22 \mathrm{~A}$ and $21 \mathrm{~B}$ is occupied by several deeply staining bands, which are placed as a pair. Zone 20 also contains as many as 6-7 deeply stained thick bands and moderate-sized puff at the subzone 20C.

\section{Chromosome 3R (4)}

The 3R arm can be recognized by a slightly dark and granulated telomeric end. A round puff with two dark bands at the region $29 \mathrm{~B}$ is the characteristic feature seen in $3 \mathrm{R}$. The telomeric end invariably holds 5 equally spaced pairs of bands that expand from subzone 29A to 29D. In zone 30, there are dark bands present in each in subzones of region 30. Almost the entire length of this chromosome is rich in dark and light bands distributed randomly. This arm does not have any other large puffs. The centromeric end of the 3R arm has a very dark and narrow band in the most proximal part of region 37D.

\section{Chromosome 3L (5)}

Chromosomal arm $3 \mathrm{~L}$ is almost equal to arm $3 \mathrm{R}$, owing to the metacentric nature of chromosome 3 . The telomeric end can be easily recognized by its flared tip with two medium sized swellings. The puff in region $43 \mathrm{~A}$ is framed by dark bands. There is a wide granulated and slightly swelled area in subzone 44A. The pericentromeric region of the $3 \mathrm{~L}$ arm contains several small puffs in zone 38 followed by a narrow proximal end. The zones 40 to 38 possess well spaced dark bands accompanied by a large number of light and dark dotted bands spread in between. In addition to this banding pattern some of the most prominent puffs are present in zones $46,44,41,40$, and 38 . The left and the right arms are usually connected on the chromosomal preparations.

\section{Comparison of present chromosome map with the previously described maps}

Key discrepancies among the banding patterns of present ovarian nurse cell of An. stephensi, and those described previously by Coluzzi et al. [18], Gayathri and Shetty [27], Redfern [57], Sahabi et al. [59] and Sharakhova et al. [65] are highlighted in Table 1 . In chromosome arm $2 \mathrm{~L}$, region 21 exhibit one small puff with dark bands in the present chromosome map contrary to two small puffs with light bands as reported by Gayathri and Shetty [27]. An additional small puff in region $28 \mathrm{C}$ is reported in the study, which is clearly lacking in pervious maps of Sharakhova et al. [65], Gayathri and Shetty [27] and Coluzzi et al. [18]. Region 24 in the current photomap and the map prepared by Gayathri and Shetty [27] is extended to form puff. However, such a puff is absent in photomap of Sharakhova et al. [65] and is replaced with dark bands in photomap of Coluzzi et al. [18]. In arm $2 \mathrm{R}$ absence of puff with two dark bands in region 13 is reported in present chromosome map. Absence of puff in zone 34-35 of chromosome arm $3 \mathrm{R}$ is one of the prominent observations of the present chromosome map, which were mostly described as present in other maps. 
Table 1 Degree of association between present ovarian nurse cell photomap and previous maps

\begin{tabular}{|c|c|c|c|c|c|c|}
\hline $\begin{array}{l}\text { Chromo- } \\
\text { some } \\
\text { arm }\end{array}$ & $\begin{array}{l}\text { Present ovarian nurse } \\
\text { cell map }\end{array}$ & Sharakhova et al. [65] & $\begin{array}{l}\text { Gayathri and Shetty } \\
\text { [27] }\end{array}$ & Redfern [57] & Sahabi et al. [59] & Coluzzi et al. [18] \\
\hline $\mathrm{X}$ & - & - & - & - & - & - \\
\hline \multirow[t]{6}{*}{$2 \mathrm{~L}$} & $\begin{array}{l}\text { Contain one small } \\
\text { puff with dark bands } \\
\text { in region } 21\end{array}$ & $\begin{array}{l}\text { Puff absent in region } \\
21\end{array}$ & $\begin{array}{l}\text { Contain two small } \\
\text { puffs in the centre } \\
\text { of region } 21 \text { with } \\
\text { light bands }\end{array}$ & - & Present & - \\
\hline & $\begin{array}{l}\text { Region } 24 \text { is } \\
\text { expanded to form } \\
\text { a puff }\end{array}$ & Absent & $\begin{array}{l}\text { Region } 24 \text { is } \\
\text { expanded to form } \\
\text { a puff }\end{array}$ & - & - & $\begin{array}{l}\text { Puffs absent in region } \\
24 \text {, dark bands are } \\
\text { present instead }\end{array}$ \\
\hline & $\begin{array}{l}\text { Absence of puff in } \\
\text { middle of region } 25\end{array}$ & Absent & Present & - & - & Present \\
\hline & $\begin{array}{l}\text { Puff with light bands } \\
\text { in the region } 26 \mathrm{~B}\end{array}$ & Present & Absent & - & - & Absent \\
\hline & $\begin{array}{l}\text { Telomeric end of the } \\
\text { 2L arm contains two } \\
\text { dark, narrow bands } \\
\text { in the proximal part } \\
\text { of region } 28 \mathrm{~A}\end{array}$ & $\begin{array}{l}\text { Telomeric end of the } \\
2 \mathrm{~L} \text { arm contains two } \\
\text { dark, narrow bands } \\
\text { in the proximal part } \\
\text { of region } 28 \mathrm{~A}\end{array}$ & $\begin{array}{l}\text { Telomeric end of the } \\
\text { 2L arm contains two } \\
\text { dark, narrow bands } \\
\text { in the proximal part } \\
\text { of region } 28 \mathrm{~A}\end{array}$ & - & - & - \\
\hline & $\begin{array}{l}\text { Small puff present in } \\
\text { the region } 28 \mathrm{C}\end{array}$ & Absent & Absent & - & - & Absent \\
\hline \multirow[t]{3}{*}{$2 \mathrm{R}$} & $\begin{array}{l}\text { Absence of puff with } \\
\text { two dark bands in } \\
\text { region } 13\end{array}$ & Absent & Present & - & - & Absent \\
\hline & $\begin{array}{l}\text { Small puff observed } \\
\text { in } 19 \mathrm{D}\end{array}$ & Absent & Present & - & Present & Present \\
\hline & $\begin{array}{l}\text { Puff present in region } \\
18 \mathrm{C}\end{array}$ & Present & Present & - & - & Absent \\
\hline \multirow[t]{3}{*}{$3 \mathrm{R}$} & $\begin{array}{l}\text { Light and narrow } \\
\text { bands in region } \\
33 \mathrm{~B}\end{array}$ & Present & Present & - & $\begin{array}{l}\text { Dark bands in zone } \\
33\end{array}$ & Dark bands in zone 33 \\
\hline & $\begin{array}{l}\text { Puffs absent in zone } \\
34,35\end{array}$ & Present & Present & - & Present & - \\
\hline & $\begin{array}{l}\text { Zone } 36 \text { contain two } \\
\text { puffs }\end{array}$ & Absent & Present & - & & Present \\
\hline \multirow[t]{2}{*}{$3 \mathrm{~L}$} & $\begin{array}{l}\text { Presence of puff in } \\
\text { region } 43 \mathrm{~A}\end{array}$ & Present & Absent & - & Present & Present \\
\hline & $\begin{array}{l}2 \text { Dark bands in } \\
\text { region 44B }\end{array}$ & Absent & Absent & Present & - & Present \\
\hline
\end{tabular}

Polytene chromosomes are found in larval salivary glands of An. stephensi, transiently appearing during mid to late 4th larval instar [49]. They are present in several tissues of mosquitoes, including salivary gland, gut, Malpigian tubules and in the ovarian nurse cells of the adult females during the gonotrophic (post-blood meal) cycle [7, 17, 57, 68]. The polytene chromosomes of an ovarian nurse cell have been an ideal material for cytogenetic investigations because of the simplicity with which preparations can be made and also due to the fact that the chromosomes are of superior morphology compared to those in larval salivary glands [41, 53, 57, 82].

Our photomap showed chief adaptation in some of the key features of banding pattern as described in photomap of An. stephensi by Coluzzi et al. [18]. The key alteration in banding/puffing observed in our preparation were, absence of puff in region 25; presence of small puff in region $28 \mathrm{C}$ and 26B; substitution of puff by dark bands in region 24 of chromosome arm 2L. In chromosome arm $2 \mathrm{R}$, we have reported a puff in the region $18 \mathrm{C}$ which is absent in the photomap of Coluzzi et al. [18]. Dark band in zone 33 which is notable feature of chromosome arm 3R of An. stephensi [18] was identified as light bands consistently in our preparation.

Detailed and clear description of ovarian nurse cell chromosome with numbered divisions and lettered subdivisions is developed by Sharakhova et al. [65]. We also made an attempt to highlight the modifications while comparing with our photomap. In chromosome arm 2L; we reported consistent small puffs in region 21, 24 and 28. Similarly, a small 
puff was observed in region 19D in $2 \mathrm{R}$ arm. Presence of puff in zone 34 and 35 of chromosome arm $3 \mathrm{R}$ were prominent in photomap of Sharakhova et al. [65], which was absent in our photomap. We also report the presence of two dark bands in region 44B in our photomap. This difference may be attributed to several compounding factors such as time and geographic localization. However, evolutionary force acting on chromosome for adaptation cannot be ruled out. We also compared this photomap with the photomap of $A n$. stephensi earlier published from our laboratory by Gayathri and Shetty [27]. Anopheles stephensi strain used for the polytene chromosome preparation then and in the present study is originated from related geographical area (i.e. Bangalore, India). However, despite of this similarity in their origin, we have reported few modifications that might have occurred in the chromosome over the time. Changes in puffing and banding pattern were reported in region $21,25,26 \mathrm{~B}$ and $28 \mathrm{C}$ of $\operatorname{arm} 2 \mathrm{~L}$; region 13 of arm $2 \mathrm{R}$; region 34,35 of arm $3 \mathrm{R}$ and region 43A, 44B of chromosome arm 3L. Such changes were reliable throughout chromosome preparation. Nevertheless, detailed genomic studies are required in order to elucidate the structural and functional basis of such differences before they are taken as indication of evolutionary changes corresponding to genetic locus or gene. It is important to have such relative data on polytene chromosomes especially in species which are of significant important vector of disease in order to identify the key evolutionary changes that might have occurred over the time.

Several cytogenetic maps have been developed for $A n$. stephensi for use in cytotaxomony and population genetics studies. Coluzzi et al. [18] was the first one to publish photomap of the ovarian nurse cell chromosomes of An. stephensi, with clearer banding pattern than the salivary gland chromosome. This map was divided into 46 numbered divisions spread across arm X, 2R, 2L, 3R and 3L. This fact made ovarian nurse cell polytene chromosomes more favorable material for mosquito cytogenetic studies as mentioned earlier. Later, a standard photomap was developed by Mahmood and Sakai [43] with numbered division and subdivisions. Researchers have periodically developed photomap from ovarian nurse cell polytene chromosome of An. stephensi using them for a deeper understanding of chromosome banding pattern and for identification of inversion polymorphisms [27, 57, 59, 65, 67]. However, one of the finest straightened high-resolution images of polytene chromosomes in $A n$. stephensi, with numbered divisions and lettered subdivisions was developed by Sharakhova et al. [65] for studying genome organization [67]. Polytene chromosome has been described for several other important Anopheline species like An. gambiae [20, 21], An. subpictus [15, 62], An. quadrimaculatus [35], An. darling [54], An. funestus [64] and An. nili [66], also for other chief vector species of Culex vishnui [14], Culex pipens [80], Aedes aegypti [8, 69] etc.

In light of practical application, chromosome photomaps have been widely used in understanding the phylogenetic relationship and identification of sibling species $[3,5,13$, 17]. They are also largely used in locating breakpoints for inversions that are present in natural as well as laboratory populations [18, 19, 28, 42]; so as to assist in our understanding of the genetic structure of populations. The detection of insecticide resistance especially among malaria vectors have led to a series of investigations on potential association of this phenomenon with chromosomal inversions. Chromosome photomap has been used with the localization of the breakpoints of several polymorphic inversions associated with insecticide resistance [4, 22, 44, 45, 51]. We have shown sixteen insecticide resistance associated inversions in An. stephensi, out of which, eleven inversions are largely augmented in $2 \mathrm{R}$ chromosomal arm (Table 2). To make this map applicable for population genetic studies of An. stephensi in future, we have indicated breakpoints for eleven paracentric inversions described in the natural population and sixteen insecticide resistance associated inversions in a schematic representation (Fig. 2). Such knowledge of the chromosomal location of genes or any other markers through such breakpoints using chromosome photomap may have important implication in evolutionary genomics; mapbased cloning studies and preparation of physical maps for transcriptome studies among medically important mosquito species. 
Table 2 List of chromosomal inversions from natural strains and insecticide resistant strains of An. stephensi, reported from our laboratory

\begin{tabular}{|c|c|c|c|c|c|}
\hline S. No. & Strains of An. stephensi & $\begin{array}{l}\text { Chromosomal } \\
\text { arm involved }\end{array}$ & Tentative breakpoints & Inversion type & References \\
\hline \multicolumn{6}{|c|}{ Inversions in natural population of An. stephensi } \\
\hline 1 & Bangalore & $2 \mathrm{R}$ & $\mathrm{b} /+$ & Heterozygous paracentric & Gayathri and Shetty [28] \\
\hline 2 & Kannur & 2R, 2L, 3R. 3L & $\mathrm{b} /+; \mathrm{g} /+; \mathrm{h} /+; \mathrm{e} /+; \mathrm{k} /+$ & Heterozygous paracentric & Gayathri and Shetty [28] \\
\hline 3 & Delhi & $2 \mathrm{R}$ & $\mathrm{b} /+$ & Heterozygous paracentric & Gayathri and Shetty [28] \\
\hline 4 & Mandya & $2 \mathrm{R} / 2 \mathrm{~L}$ & $\mathrm{~b} /+$ & Heterozygous paracentric & Gayathri and Shetty [28] \\
\hline 5 & Pune & $2 \mathrm{R}$ & $\mathrm{b} /+$ & Heterozygous paracentric & Gayathri and Shetty [28] \\
\hline \multicolumn{6}{|c|}{ Inversions in insecticide resistant strains of An. stephensi } \\
\hline 6 & DDT Resistant & $2 \mathrm{R}$ & $\mathrm{i} /+$ & Heterozygous paracentric & Chandrakala and Shetty [10] \\
\hline 7 & Carbofuran resistant & $3 R$ & $\mathrm{~d} /+$ & Heterozygous paracentric & Shetty et al. (Unpublished data) \\
\hline 8 & Propoxur resistant & $2 \mathrm{R}$ & $\mathrm{n} /+$ & Heterozygous paracentric & Sanil and Shetty [61] \\
\hline 9 & Propoxur resistant & $3 R$ & $\mathrm{f} /+; \mathrm{g} /+$ & Heterozygous paracentric & Sanil and Shetty [61]. \\
\hline 10 & Chlorpyrifos resistant & $2 \mathrm{R}$ & $\mathrm{j} /+$ & Heterozygous paracentric & Chandrakala and Shetty [11] \\
\hline 11 & Temephos resistant & $2 \mathrm{R}$ & $\mathrm{o} /+$ & Heterozygous paracentric & Sanil and Shetty [60]. \\
\hline 12 & Temephos resistant & $3 R$ & $\mathrm{~h} /+; \mathrm{i} /+$ & Heterozygous paracentric & Sanil and Shetty [60] \\
\hline 13 & Alphamethrin resistant & $2 \mathrm{R}$ & $\mathrm{b} /+$ & Heterozygous paracentric & Shetty et al. [72] \\
\hline 14 & Bifenthrin resistant & $2 \mathrm{R}$ & $\mathrm{m} /+$ & Heterozygous paracentric & Zin et al. [84] \\
\hline 15 & Cyfluthrin resistant & $2 \mathrm{R}$ & $\mathrm{k} /+$ & Heterozygous paracentric & Chandrakala and Shetty [12] \\
\hline 16 & Deltamethrin resistant & $2 \mathrm{R}$ & $1 /+$ & Heterozygous paracentric & Rajshree and Shetty [55] \\
\hline 17 & Neem resistant & $3 \mathrm{~L}$ & $a /+$ & Heterozygous paracentric & Zin et al. [83] \\
\hline 18 & Fenitrothion resistant & $2 \mathrm{R}$ & $\mathrm{g} /+; \mathrm{h} /+$ & Heterozygous paracentric & Ghosh and Shetty [29] \\
\hline 19 & Fenitrothion resistant & $2 \mathrm{~L}$ & $g /+$ & Heterozygous paracentric & Ghosh and Shetty [29] \\
\hline
\end{tabular}

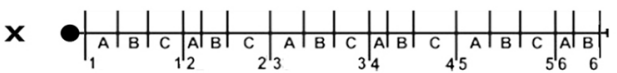
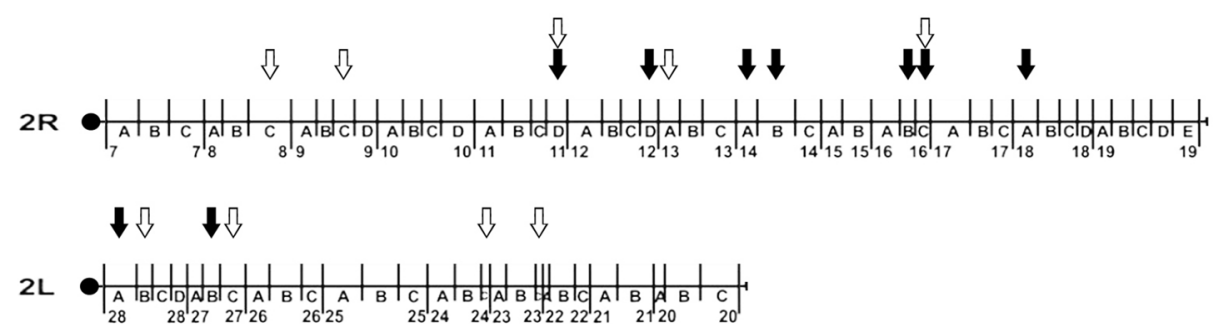

$\downarrow \downarrow \downarrow \downarrow \downarrow \downarrow \downarrow \downarrow \downarrow \downarrow \downarrow$

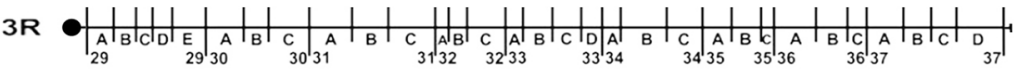

TENTATIVE BREAKPOINTS
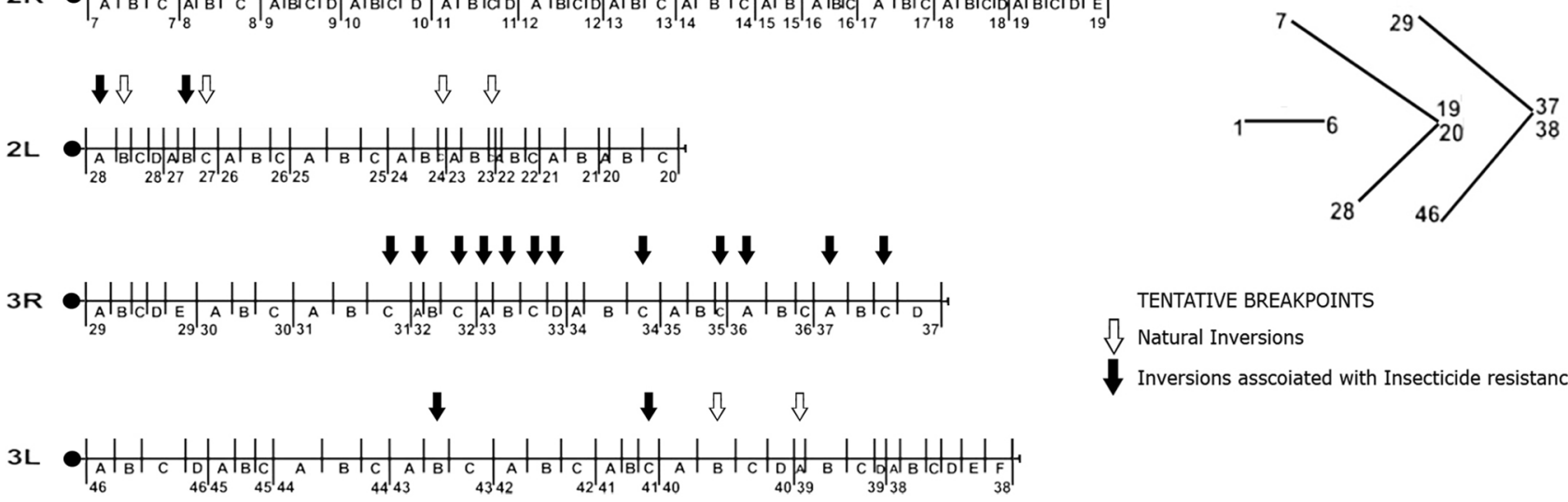

ת Natural Inversions

Inversions asscoiated with Insecticide resistance

Fig. 2 A schematic representation indicating breakpoints for paracentric inversions in the natural population and insecticide resistant strains of An. stephensi studied in our laboratory

Acknowledgements D Sanil and V Shetty are grateful to the Poornaprajna Institute of Scientific Research (PPISR), Bidalur Campus, Devanahalli, Bangalore, for research fellowships. The authors also acknowledge the Department of Science and Technology (DST) for financial assistance. 


\section{Compliance with ethical standards}

Conflict of interest The authors declare that there is no conflict of interest.

\section{References}

1. Abraham EG, Islam S, Srinivasan P, Ghosh AK, Valenzuela JG, Ribeiro JMC, et al. Analysis of the Plasmodium and Anopheles transcriptional repertoire during ookinete development and midgut invasion. J Biol Chem. 2004;279:5573-80.

2. Baimai V. Population cytogenetics of the malaria vector Anopheles leucosphyrus group. Southeast Asian J Trop Med Public Health. 1988;19:667-80.

3. Beebe NW, Cooper RD. Systematics of malaria vectors with particular reference to the Anopheles punctulatus group. Int J Parasitol. 2000;30:1-17.

4. Benedict MQ, McNitt LM, Cornel AJ, Collins FH. A new marker, black, a useful recombination suppressor in (2) 2, and a balanced lethal for chromosome 2 of the mosquito Anopheles gambiae. Am J Trop Med Hyg. 1999;61:618-24.

5. Besansky NJ. Complexities in the analysis of criptic taxa within the genus Anopheles. Parasitologia. 1999;41:97-100.

6. Brogdon WG, McAllister JC. Insecticide resistance and vector control. Emerg Infect Dis. 1998;4:605-13.

7. Campos J, Andrade CFS, Recco-Pimentel SM. Malpighian tubule polytene chromosomes of Culex quinquefasciatus (Diptera, Culicinae). Mem Inst Oswaldo Cruz. 2003;98:383-6.

8. Campos J, Andrade CF, Recco-Pimentel SM. A technique for preparing polytene chromosomes from Aedes aegypti (Diptera: Culicinae). Mem Inst Oswaldo Cruz. 2003;98:387-90.

9. Catteruccia F, Holan T, Loukeris TG, Blass C, Savakis C, Kafatos FC, et al. Stable germline transformation of the malaria mosquito Anopheles stephensi. Nature. 2000;405:959-62.

10. Chandrakala BN, Shetty NJ. Genetic studies of DDT resistance in the malaria mosquito Anopheles stephensi Liston. J Cytol Genet. 2004;5:185-90.

11. Chandrakala BN, Shetty NJ. Genetic studies of chlorpyrifos resistance in the malaria mosquito Anopheles stephensi Liston. J Cytol Genet. 2006;7:155-60.

12. Chandrakala BN, Shetty NJ. Genetic studies of cyfluthrin resistance in Anopheles stephensi Liston-a malaria mosquito. In: Sobti (ed) Proceedings of Prof. G. P. Sharma felicitation: new trends in life sciences. Punjab University, Chandigarh, pp $48-52 ; 2006 \mathrm{~b}$.

13. Chaudhary S, Soni KG. Salivary X-Chromosome in two allopatric populations of Anopheles subpictus Grassi from India. In: Sidhu DS, Singh D, editors. Advances in medicine zoology-Procesdings of the 5th International Symposium on vectors and vector borne diseases. Patiala: Publication Bureau, Punjabi University; 2000. p. 109-11.

14. Chaudhry S. The salivary gland chromosomes of Culex (Culex) vishnui (Culicidae:Diptera). Genetica. 1981;55:171-8.

15. Chaudhry S, Neetu GS, Chhilar JS. Salivary polytene chromosome mapping of Anopheles (Cellia) subpictus Grassi (Culicidae:Diptera). Genome. 2005;48:241-6.

16. Collins FH, Paskewitz SM. A review of the use of ribosomal DNA (rDNA) to differentiate among cryptic Anopheles species. Insect Mol Biol. 1996;5:1-9.

17. Coluzzi M, Kitzmiller JB. Anopheline mosquitoes. In: King RC, editor. Handbook of genetics. New York: Plenum Publishing Corporation; 1975. p. 285-309.
18. Coluzzi M, Cancrini G, Di Deco M. The polytene chromosomes of Anopheles superpictus and relationships with Anopheles stephensi. Parassitogia. 1970;12:101-12.

19. Coluzzi M, Di Deco M, Cancrini G. Chromosomal inversions in Anopheles stephensi. Parassitologia. 1973;15:129-36.

20. Coluzzi M, Sabatini A, Della Torre A, Di Deco MA, Petrarca V. A polytene chromosome analysis of the Anopheles gambiae species complex. Science. 2002;298:1415-8.

21. Coluzzi M, Sabatini A, Petraca V, Di Deco MA. Chromosomal differentiation and adaptation to human environments in the Anopheles gambie complex. Trans R Soc Trop Med Hyg. 1979;73:483-97.

22. D’Alessandro G, Frizzi G, Mariani M. Effect of DDT selection pressure on the frequency of chromosomal structures in Anopheles atroparvus. Bull World Health Organ. 1957;16:859-64.

23. Dimopoulos G, Zheng L, Kumar V, della Torre A, Kafatos FC, Louis C. Anopheles gambiae: use of RAPD polymorphisms for genetic, cytogenetic and STS landmarks. Genetics. 1996;143:953-60.

24. Favia G, Louis C. Molecular identification of chromosomal forms of Anopheles gambiae sensu stricto. Parassitologia. 1999;41:115-8.

25. French WL, Baker RH, Kitzmiller JB. Preparation of mosquito chromosomes. Mosq News. 1962;22:377-83.

26. Gale KR, Crampton JM. DNA probes for species identification of mosquitoes in the Anopheles gambiae complex. Med Vet Entomol. 1987;1:127-36.

27. Gayathri DK, Shetty NJ. Polytene chromosomes of Anopheles stephensi Liston a malaria vector. Vignana Bharathi. 1989;121:1-8.

28. Gayathri DK, Shetty NJ. Chromosomal inversions in Anopheles stephensi Liston-a malaria mosquito. J Cytol Genet. 1992;27:153-61.

29. Ghosh C, Shetty NJ. Tests for association of fenitrothion resistance with inversion polymorphism in the malaria vector, Anopheles stephensi. The Nucleus. 2004;47:164-8.

30. Green CA. Cytological maps for the practical identification of the fresh water species of the Anopheles gambiae complex. Ann Trop Med Parasit. 1972;64:131-6.

31. Green CA, Miles SJ. Chromosomal evidence for sibling species of the malaria vector Anopheles (Cellia) culicifacies Giles. J Trop Med Hyg. 1980;83:75-8.

32. Han YS, Thompson J, Kafatos FC, Barillas-Mury C. Molecular interactions between Anopheles stephensi midgut cells and Plasmodium berghei: the time bomb theory of ookinete invasion of mosquitoes. EMBO J. 2000;19:6030-40.

33. Hemingway J, Ranson $\mathrm{H}$. Insecticide resistance in insect vectors of human disease. Ann Rev Entomol. 2000;45:371-91.

34. Hill SM, Crampton JM. DNA based methods for the identification of insect vectors. Ann Trop Med Parasitol. 1994;88:227-50.

35. Kaiser PE, Seawright JA. The ovarian nurse cell polytene chromosomes of Anopheles quadrimaculatus species. A J Am Mosq Control Assoc. 1987;3:222-30.

36. Keppler WJ, Kitzmiller JB, Rabbani MG. The salivary gland chromosomes of Anopheles albimanus. J Am Mosq Control Assoc. 1973;33:42-9.

37. Kitzmiller JB. Genetics, cytogenetics and evolution of mosquitoes. Adv Genet. 1976;18:315-433.

38. Kocsis E, Trus BL, Steer CJ, Bisher ME, Steven AC. Image averaging of flexible fibrous macromolecules: the clathrin triskelion has an elastic proximal segment. J Struct Biol. 1991;107:6-14.

39. Krimbas CB, Powell JR. Drosophila inversion polymorphism. Boca Ratan: CRC Press; 1992.

40. Lim J, Gowda DC, Krishnegowda G, Luckhart S. Induction of nitric oxide synthase in Anopheles stephensi by Plasmodium falciparum: mechanism of signaling and the role of parasite glycosylphosphatidylinositols. Infect Immun. 2005;73:2778-89. 
41. Macgregor HC, Varley JM. Working with animal chromosomes. NY: Wiley; 1983.

42. Mahmood F, Sakai RK. Inversion polymorphisms in natural populations of Anopheles stephensi. Can J Genet Cytol. 1984;26:538-46.

43. Mahmood F, Sakai RK. An ovarian chromosome map of Anopheles stephensi. Cytobios. 1985;43:79-86.

44. Mosna E, Palmieri C, Ascher KRS, Rivosecchi L, Neri I. Chromosome arrangements in laboratory-developed DDT-Resistant strains of Anopheles atroparvus. Bull World Health Organ. 1959;20:63-74.

45. Mosna E, Rivosecchi L. Ascher KRS. Studies on insecticide resistant anophelines. 1. Chromosome arrangements in a dieldrin selected strain of Anopheles atroparvus. Bull World Health Organ. 1958;19:297-301.

46. Munstermann LE. Mosquito systematic: current status, new trends, associated complications. J Vector Ecol. 1995;20:129-38.

47. Murray CJL, Rosenfeld LC, Lim SS, Andrews KG, Foreman KJ, Haring D, et al. Global malaria mortality between 1980 and 2010: a systematic analysis. Lancet. 2012;379:413-31.

48. Narang SK, Klein TA, Perera OP, Lima JB, Tang AT. Genetic evidence for the existence of cryptic species in the Anopheles albitarsis complex in Brazil: allozymes and mitochondrial DNA restriction fragment length polymorphisms. Biochem Genet. 1993;31:97-112.

49. Nath BB, Lakhotia SC. Heat shock response in ovarian nurse cells of Anopheles stephensi. J Biosci. 1989;14:143-52.

50. Nchinda TC. Malaria: a reemerging disease in Africa. Emerg Infect Dis. 1989;4:398-403.

51. Nigatu W, Curtis CF, Lulu M. Test for association of DDT resistance with inversion polymorphism in Anopheles arabiensis from ethiopia. J Am Mosq Control Assoc. 1995;1:238-40.

52. Paris M, Boyer S, Bonin A, Collado A, David J, Despres L. Genome scan in the mosquito Aedes rusticus: population structure and detection of positive selection after insecticide treatment. Mol Ecol. 2010;19:325-37.

53. Powell JR. Progress and prospects in evolutionary biology. The drosophila model. Oxford: Oxford University Press; 1997.

54. Rafael MS, Rohde C, Bridi LC, Valente Gaiesky VL, Tadei WP. Salivary polytene chromosome map of Anopheles darlingi, the main vector of neotropical malaria. Am J Trop Med Hyg. 2010;83:241-9.

55. Rajashree BH, Shetty NJ. Genetic study of deltamethrin resistance in the malaria mosquito Anopheles stephensi Liston. J Parasit Dis. 1998;22:140-3.

56. Ramirez CCL, Dessen EMB. Chromosome differentiated populations of Anopheles cruzii: evidence for third sibling species. Genetica. 2000;108:73-80.

57. Redfern CPF. DNA replication in polytene chromosomes: similarity of termination patterns in somatic and germ-line derived polytene chromosomes of Anopheles stephensi liston (Diptera: Culicidae). Chromosoma. 1981;84:33-47.

58. Reinert JF, Kaiser PE, Seawright JA. Analysis of the Anopheles (Anopheles) quadrimaculatus complex of sibling species (Diptera: Culicidae) using morphological, cytological, molecular, genetic, biochemical, and ecological techniques in an integrated approach. J Am Mosq Control Assoc. 1997;13:1-102.

59. Sahabi Z, Amirkhanian JD, Shahgoudian E. The polytene chromosomal pattern of Anopheles stephensi mysorensis of Kazeroon (Iran). Iranian J Public Health. 1974;2:194-8.

60. Sanil D, Shetty NJ. Genetic study of temephos resistance (tr), an organophosphate insecticide in the malaria mosquito, Anopheles stephensi Liston. J Cytol Genet. 2009;11:15-22.

61. Sanil D, Shetty NJ. Genetic study of propoxur resistance-a carbamate insecticide in the malaria mosquito. Anopheles stephensi Liston. Malar Res Treat. 2010. https://doi.org/10.4061/2010/502824.
62. Seetharam PL, Chowdaiah BN. Chromosome studies on oriental anophelines. III. The salivary gland chromosomes of Anopheles subpictus. Proc Indian Natl Sci Acad. 1974;40:399-403.

63. Sharakhov IV, Sharakhova MV. Cytogenetic and physical mapping of mosquito genome. In: Verrity JE, Abbington LE, editors. Chromosome mapping research developments. New York.: Nova Science Publishers; 2008. p. 35-76.

64. Sharakhov IV, Sharakhova MV, Mbogo CM, Koekemoer LL, Yan G. Linear and spatial organization of polytene chromosomes of the African malaria mosquito Anopheles funestus. Genetics. 2001;159:211-8.

65. Sharakhova MV, Xia A, McAlister SI, Sharakhov IV. A standard cytogenetic photomap for the mosquito Anopheles stephensi (Diptera: Culicidae): application for physical mapping. J Med Entomol. 2006;43:861-6.

66. Sharakhova MV, Antonio-Nkondjio C, Xia A, Ndo C, AwonoAmbene P, Simard F, Sharakhov IV. Cytogenetic map for Anopheles nili: application for population genetics and comparative physical mapping. Infect Genet Evol. 2011;11:746-54.

67. Sharakhova MV, Xia A, Tu Z, Shouche YS, Unger MF, Sharakhov IV. A physical map for an Asian malaria mosquito, Anopheles stephensi. Am J Trop Med Hyg. 2010;83:1023-7.

68. Sharma GP, Chaudhry S, Chaudhry A. Studies on the salivary gland chromosomes of an isolated population of Anopheles stephensi (Diptera, Culicidae). Cytobios. 1977;20:35-41.

69. Sharma GP, Mittal OP, Chaudhry S, Pal V. A preliminary map of the salivary gland chromosomes of Aedes (stegomyia) aegypti (Culicadae, Diptera). Cytobios. 1978;22:169-78.

70. Shetty NJ. Chromosomal translocation and semisterility in the malaria vector Anopheles fluviatilis James. Ind J Malariol. $1983 ; 20: 45-8$

71. Shetty NJ. The genetic control of Anopheles stephensi-a malaria mosquito. In: Raghunath D, Nayak R, editors. Trends in malaria and vaccine research: the current scenario. New Delhi: TataMcGraw-Hill; 2002. p. 44-79.

72. Shetty NJ, Hariprasad TP, Sanil D, Zin T. Chromosomal inversions among insecticide-resistant strains of Anopheles stephensi Liston, a malaria mosquito. Parasitol Res. 2013;112:3851-7.

73. Singh P, Singh BN. Population genetics of Drosophila ananassae: evidence for population sub-structuring at the level of inversion polymorphism in Indian natural population. Int $\mathbf{J}$ Biol. 2010;2:19-28.

74. Subbarao SK. Genetics of malaria vectors. Proc Natl Acad Sci India. 1996;66:57-76.

75. Subbarao SK, Sharma VP. Anopheline species complexes and malaria control. Ind J Med Res. 1997;106:164-73.

76. Subbarao SK, Vasantha K, Adak T, Sharma VP. Anopheles culicifacies complex: evidence for a new sibling species, species C. Ann Entomol Soc Am. 1983;76:985-8.

77. Subbarao SK, Vasantha K, Sharma VP. Cytotaxonomy of certain malaria vectors in India. In: Service MW, editor. Biosystematics of haematophagous insects. Systematics Association Special. Oxford: Oxford Clarendon Press; 1988. p. 25-37.

78. Suguna SG. Cytological and morphological evidence for sibling species in Anopheles subpictus Grassi. J Commun Dis. 1982;14:1-18.

79. Tabachnick WJ, Black WC. Population genetics in vector biology. In: Beaty BJ, Marquardt WC, editors. The biology of disease vectors. Niwot: University Press of Colorado; 1996. p. 417-37.

80. Tewfik HR, Barr AR. The salivary gland chromosomes of Culex pipiens L. Mosq News. 1974;34:47-54.

81. Wondji C, Morgan J, Coetzee M, Hunt RH, Steen K, Black WC, Hemingway J, Ranson H. Mapping a quantitative trait locus (QTL) conferring pyrethroid resistance in the African malaria vector Anopheles funestus. BMC Genom. 2007;8:34. https://doi. org/10.1186/1471-2164-8-34. 
82. Zhimulev IF. Morphology and structure of polytene chromosomes. In: Hall JC, Dunlap JC, Freidmann T, Giannelli F, editors. Advances in genetics, vol. 34. San Deigo: Academic Press; 1996. p. 1-497.

83. Zin T, Minn MZ, Shetty NJ. Estimation of proteins and enzymes in different developmental stages of neem susceptible and resistant strains of Anopheles stephensi Liston, 1901. Univ Res J. 2008;1:185-93.

84. Zin T, Minn MZ, Shetty NJ. Biochemical basis of bifenthrin resistance in Anopheles stephensi Liston 1901, a malaria mosquito. J Myanmar Acad Arts Sci. 2009;2:121-30. 